\title{
HUBUNGAN PARITAS, PENOLONG PERSALINAN DAN JARAK KEHAMILAN DENGAN ANGKA KEMATIAN BAYI DI JAWA TIMUR
}

\author{
Renaldi Kurniawan ${ }^{1}$, Soenarnatalina Melaniani ${ }^{2}$ \\ ${ }^{1,2}$ Departemen Biostatistika dan Kependudukan \\ Fakultas Kesehatan Masyarakat \\ Universitas Airlangga \\ Jl. Dr. Ir. H. Soekarno, Mulyorejo, Kota Surabaya, Jawa Timur \\ Email: renaldikaraa@gmail.com
}

\begin{abstract}
Infant mortality is a major component in determining the health and well-being of a community in a country. Indonesia Health Demographic Survey in 2012 shows that infant mortality rate in Indonesia is 32 babies per 1000 live births. Infant mortality rate in eastern Java is 26 babies per 1000 live births. Infant mortality is caused by external factors and internal factors. Parity, gestational distance and birth attendant are the factors chosen to be analyzed. The objectives of the study were to analyze the relationship of parity, birth spacing and birth attendant to infant mortality rate in East Java. The type of research that is analytical research using non-reactive approach. The study took the data of the 2012 IDHS Female Woman Never married. Sampling followed the 2012 IDHS plus inclusion criteria from the researchers. The number of samples of the study was 591 mothers with a history of dead infants during the survey. The study took the data of the 2012 SDKI Female Woman Never married. Data analysis was done by multiple logistic regression. The results of the simple logistic regression analyzes have shown an association between parity> 2 children, birth attendants instead by a health professional, pregnancy spacing $\leq 4$ years and spacing of pregnancy $>4$ years. All independent variables entered as a candidate for the multiple logistic regression analysis of the results of the multiple logistic regression analysis was parity shows, their relationship with infant mortality with $p$ value $=0.001$, but at birth attendant with a $p$ value of 0.66 . Screening risks of pregnant mothers and handling of ill toddlers by midwives and IEC to mothers about nutrition, pregnancy care and infant care through counseling, leaflets and posters.
\end{abstract}

Keywords: parity, birthage, birth support, infant mortality

\begin{abstract}
ABSTRAK
Kematian bayi adalah komponen utama dalam menentukan derajat kesehatan dan kesejahteraan suatu masyarakat di suatu negara. Hasil Survei Demografi Kesehatan Indonesia tahun 2012 menunjukkan bahwa angka kematian bayi di Indonesia sebesar 32 bayi tiap 1000 kelahiran kelahiran hidup. Angka kematian bayi di jawa timur sebesar 26 bayi tiap 1000 kelahiran hidup. Kematian bayi diakibatkan oleh faktor luar dan faktor dalam. Paritas, jarak kehamilan dan penolong persalinan adalah faktor yang dipilih untuk dianalisis. Tujuan penelitian adalah menganalisis hubungan paritas, jarak kelahiran dan penolong persalinan dengan angka kematian bayi di Jawa Timur. Jenis penelitian yang adalah penelitian analitik menggunakan pendekatan non reaktif. Penelitian mengambil data SDKI 2012 bagian Wanita Pernah Kawin. Pengambilan sampel mengikuti SDKI 2012 ditambah kriteria inklusi dari peneliti. Besar sampel penelitian adalah 591 ibu dengan riwayat bayi mati saat survei dilakukan. Penelitian mengambil data SDKI 2012 bagian Wanita Pernah Kawin. Analisis data dilakukan dengan regresi logistik berganda. Hasil analisis regresi logistik sederhana menunjukkan adanya hubungan antara paritas anak lebih dari dua, penolong persalinan bukan oleh petugas kesehatan, jarak kehamilan $\leq 4$ tahun dan jarak kehamilan > 4 tahun. Semua variabel independen masuk sebagai kandidat untuk analisis regresi logistik berganda. Hasil dari analisis regresi logistik berganda adalah paritas menunjukan adanya hubungan dengan angka kematian bayi dengan $\mathrm{p}$ value $=0,001$, namun pada penolong persalinan dengan $\mathrm{p}$ value 0,66 . Screning risiko ibu yang sedang hamil dan penanganan balita sakit oleh bidanserta KIE kepada ibu tentang gizi, perawatan kehamilan dan perawatan bayi melalui penyuluhan, leaflet, dan poster.
\end{abstract}

Kata kunci: paritas, jarak kelahiran, penolong persalinan, angka kematian bayi

\section{PENDAHULUAN}

Pembangunan kesehatan memiliki tujuan supaya derajat kesehatan masyarakat meningkat dan sesuai target yang ditetapkan dalam tujuan nasional. Angka kematian bayi menjadi aspek dasar yang masih belum dapat memenuhi target yang ditetapakan. Pemerintah 
menyebutkan bahwa sebagai langkah awal menuju bangsa yang mandiri memerlukan pembangunan SDM terutama pada aspek kesehatan (Sitorus, 2009). Program pembangnan kesehatan yang dicanangkan dan dilaksankan membuat peningkatan derajat kesehatan masyarakat telah banyak tercapai, meskipun pada aspek angka kematian bayi masih dijumpai berbagai hambatan (PDPERSI, 2007).

Millenium Development Goals (MDGs) merupakan padangan secara global terkait dengan pembangunan kesehatan yang disahakan dalam KTT Milenium dengan peserta 189 negara bertempat di New York, USA pada September tahun 2000. KTT ini menghasilkan 8 target pembanguan kesehatan sebagai tujuan pokok dengan batas waktu tahun 2015 untuk menyelesaikannya. Kematian bayi sebagai indikator utama dalam menentukan derajat kesehatan pada setiap negara menjadi satu dari delapan kendala pembangunan kesehatan secara global yang dihadapi tiap negara anggota PBB yang mengikuti MDGs.

Menurunkan angka kematian bayi di Indonesia tidaklah mudah, terbukti Indonesia belum bisa memenuhi target progam millenium development goals (MDGs) yang sudah tidak berlaku hingga 2015. Banyaknya negara yang belum mencapai target, maka dibentuklah program lanjutan yang bernama program Sustainable development goals (SDGs) sebagai arah baru pembangunan derajat kesehatan di dunia. Poin ketiga dari SDGs adalah menjamin kehidupan yang sehat dan sejahtera untuk setiap umat manusia pada tiap tingkatan usia. Poin ini menjadi harapan untuk tercapainya angka kematian bayi dapat menurun hingga dibawah 70 bayi tiap 100.000 kelahiran hidup dengan batas waktu tahun 2030 (Kemenkes RI, 2015).

Kematian bayi eksogen atau kematian postneonatal merupakan kematian yang dialami bayi saat berada pada usia satu bulan sampai kurang dari usia satu tahun sebagai akibat dari faktor persalian yang kurang baik atau faktor lingkungan luar (Syafudin, 2011). Angka Kematian Bayi (AKB) adalah jumlah kematian bayi sesuai dengan tahun dan daerah yang ditentukan tiap 1000 bayi yang lahir hidup. Jumlah kematian bayi merupakan bayi yang lahir hidup namun mati pada saat setelah kelahiran bayi hingga bayi berusia kurang dari satu tahun dilihat dari segi banyaknya bayi yang meninggal (WHO, 2012). Target MDGs dalam poin kematian bayi adalah 23 kematian tiap 1.000 kelahiran hidup.

SDKI tahun 2012 menyebutkan AKB di Indonesia adalah 32 per 1.000 kelahiran hidup. Kejadian kematian bayi di Jawa Timur menjadi satu dari lima provinsi dengan jumlah kematian bayi lebih dari $50 \%$ dengan jumlah kematian bayi terbanyak di Indonesia (BPS Provinsi Jawa Timur, 2012). Kejadian kematian bayi di Jawa Timur sampaidengantahun 2015 belum memenuhi target yang termuat dalam MDG's (Dinkes Provinsi Jawa Timur, 2015).

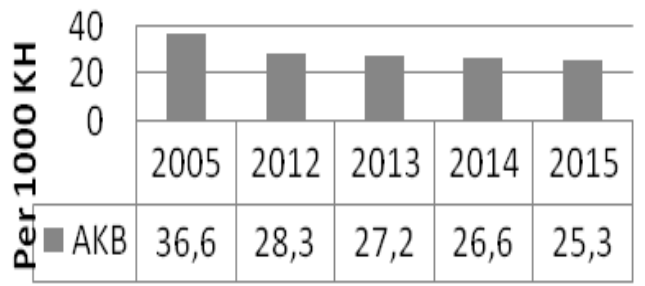

Gambar 1. AKB dari tahun 2005-2015 di Jawa Timur

Data angka kematian bayi berdasarkan SDKI 2012 menunjukkan hasil untuk kematian bayi dalam kurun waktu lima tahun sebelum survei yaitu pada tahun 2008 hingga 2012 sebanyak 32 bayi yang mengalami kematian tiap 1.000 kelahiran hidup yang terjadi. Angka tersebut dapat diartikan bahwa satu dari tiga puluh satu bayi yang lahir di Indonesia mengalami kematian sebelum berumur 1 tahun. Sebanyak $60 \%$ bayi mati pada saat masih beumur 1 bulan, apabila dijadikan AKB neonatum adalah 19 kematian tiap 1.000 kelahiran hidup. Sebanyak $80 \%$ bayi mati pada saat memasuki umur 1-11 bulan, menjadi AKB posneonatum adalah 13 kematian tiap 1.000 kelahiran hidup (BPS, 2013).

Hasil SDKI 2012 menunjukan adanya hubungan secara positif antara urutan kelahiran dan peluang bayi untuk mati. Artinya semakin meningkat urutan kelahiran bayi, maka peluang bayi untuk mati semakin tinggi. Hubungan ini terlihat pada AKB untuk kelahiran pertama adalah 35 kematian tiap 1.000 kelahiran hidup, sedangkan AKB pada kelahiran ketujuh dan kelahiran selanjutnya adalah 71 kematian tiap 1.000 kelahiran hidup (BPS, 2013).

Paritas merupakan banyaknya anak yang pernah dilahirkan seorang ibu baik yang hidup ataupun yang mati (Wang, 2012). Paritas merupakan determinan utama untuk menilai kondisi ibu yang tengah hamil dan janin yang dikandungnya dalam kurun waktu masa 
kehamilan hingga persalinan tiba (Waang, 2012), sehingga dapat disimpulkan paritas berkaitan erat dengan gangguan pada masa persalinan yang pernah dialami pada kelahiran lalu yang berakibat pada kematian bayi setelah lahir.

Penelitian yang pernah dilakukan membuktikan bahwa jarak kelahiran yang singkat membuat bayi yang dilahirkan rentan untuk mengalami kematian. Menurut Norton (2005) yang meneliti hubungan jarak kelahiran dengan risiko bayi lahir prematur mendapatkan hasil bahwasanya apabila jarak antar kelahiran kurang dari setengah tahun atau 6 bulan berhubungandengan terjadinya prematur dan BBLR, hal ini banyak dilanjutkan dengan bayi yang tidak mampu hidup hingga satu tahun.

Merujuk data SDKI 2007 rerata jarak antar kelahiran bayi di Indonesia berada pada 54 bulan hingga 53 bulan. Jarak tersebut menunjukkan bahwa rerata bayi di Indonesia masih memilikirentan lahir yang ideal, namun terdapat $29,5 \%$ ibu yang melahirkan bayi yang memiliki rentan jarak kelahiran dibawah 36 bulan. Ibu yang melahirkan dengan jarak kelahiran 36 bulan hingga 59 bulan sebanyak $25,6 \%$. Jumlah paling banyak adalah ibu yang melahirkan dengan jarak lebih dari 60 bulan yaitu sebanyak $44,8 \%$.

Kematian bayi dapat terjadi pada jarak kehamilan pendek diakibatkan pada saat ibu mengandungjanin, gizi yang diserap oleh janin melalui perantara plasenta dari tubuh ibu. Ibu yang terlalu sering hamil akan berpengaruh pada pengoptimalan pemberian gizi pada janin yang dikandung kelak. Peran ibu sangat diperlukan pada masa bayi sebelum berumur satu tahun untuk merawat kondisi bayi tersebut (Pritasari, 2013).

Ibu yang sedang mengalami kehamilan sering menghadapi kondisi psikis yang khawatir terutama menjelang persalinan, dimana kondisi kritis mungkin untuk terjadi. Fasilitas kesehatan menjadi tempat yang paling mungkin untuk memberikan pelayanan kesehatan terutama yang berkaitan dengan persalinan. Hasil Riskesdas 2013 menyatakan sebanyak $70 \%$ ibu yang bersedia melakukan persalinan di fasilitas kesehatan. Ibu yang melakukan persalinan dirumah atau lainya sebanyak $29,6 \%$. Jumlah penolong persalinan yang memiliki kompetensi dan terdaftar di Dinas Kesehatan, misalnya dokter spesialis, dokter umum dan bidan sebanyak $87,1 \%$ (Kemenkes RI, 2013).
Terjadinya suatu kematian merupakan proses alamiah yang dialami setiap mahkluk hidup. Hal yang paling wajar dan sering menyebabkan kematian adalah sakit. Studi hasil SDKI mencoba mencari faktor terjadinya kematian bayi, faktor tersebut terbagi menjadi faktor budaya lingkungan, sosial dan perilaku (Masuy-Stroobant, 2001). Misra, et.al., (2003) menyatakan perlu adanya suatu pendekatan yang saling memiliki dengan berbagai sektor dan integrasi pada lintas sektor terkait, selain itu juga bisa digunakan sebagai alat menilai faktor risiko terjadinya kematian bayi.

\section{METODE PENELITIAN}

Jenis penelitian yang diterapkan adalah penelitian analitik dengan pendekatan non reaktif. Penelitian menggunakan data SDKI 2012 yang dianalisis secara kuantitatif. Instrumen data termuat dalam kuesioner SDKI 2012 bagian Wanita Pernah Kawin (WPK), dimana cara pengumpulan data dilakukan dengan memanfaatkan data SDKI (2012).

Populasi penelitian adalah Ibu dengan bayi yang pernah dilahirkan dalam kurun waktu 0 bulan sampai dengan $<12$ bulan di Jawa Timur, sesuai dengan data SDKI (2012). Sampel penelitian terdiri dari wanita yang pernah melahirkan hingga survei dilakukan. Data sampel yang digunakan hanya pada wilayah Jawa Timur. Kriteria inklusi penelitian berupa responden wanita usai subur pada wilayah Jawa Timur yang telah menyelesaikan wawancara SDKI (2012) bagian WPK, dalam kondisi menikah monogami dan pernah melahirkan ketika kegiatan SDKI tahun 2012 dilaksanakan. Hasil dari kriteria inklusi didapatkan sampel sebanyak 591 responden.

Variabel dependen penelitian ini adalah status kematian bayi yang dikelompokkan menjadi dua ketegori yaitu Ya (coding 0) untuk ibu yang pernah melahirkan yang dilanjutkan kematian bayi dan Tidak (coding 1) untuk ibu yang pernah melahirkan tanpa kematian bayi.

Variabel independen dalam penelitian ini menggunakan paritas, penolong persalinan daan jarak kelahiran. Definisi paritas adalah jumlah anak yang pernah dilahirkan baik yang masih hidup maupun sudah mati hingga survey dilaksanakan tidak termasuk bayi yang sedang dikandung. Paritas dikelompokkan menjadi 2 kategori yaitu paritas ideal $(\leq 2$ anak) dan paritas tidak ideal (> 2 anak). Coding yang digunakan adalah 0 untuk paritas tidak ideal 
dan 1 untuk paritas ideal. Penolong persalinan merupakan orang atau instansi yang membantu dalam proses melahirkan anak terakhir, dalam hal ini penolong persalinan dikelompokkan menjadi dua yaitu yang ditolong oleh petugas kesehatan dan yang ditolong bukan oleh petugas kesehatan. Coding yang digunakan adalah 0 untuk penolong persalinan bukan petugas kesehatan dan 1 untuk penolong persalinan petugas kesehatan. Jarak kehamilan adalah jarak antara kelahiran terakhir dengan kelahiran sebelumnya, dikarenakan hanya terdapat responden yang hanya memiliki jarak kehamilan satu, maka jarak kehamilan dikelompokkan menjadi tiga kategori yaitu tidak ada kelahiran, $\leq 4$ tahun dan $>4$ tahun. Analisis data yang dilakukan dalam penelitian ini adalah analisis deskriptif dan analisis regresi logistik sederhana. Analisa deskriptif sebagai alat analisis untuk menggambarkan tabel silang yang menjelaskan gambaran dari variabel dependen dengan variabel independen. Analisis regresi logistik sederhana sebagai alat untuk mengetahui hubungan status kematian bayi dengan tiap variabel independen dalam penelitian. Analisis regresi logistik sederhana digunakan juga sebagai alat seleksi variabel yang akan digunakan untuk analisis regresi logistik berganda

Langkah dalam melakukan seleksi variabel dengan melakukan analisis antara tiap variable independen dengan variabel dependen. Hasil Uji regresi logistik sederhana mempunyai nilai $\mathrm{P}$ value < 0,25 maka variable tersebut dapat masuk model regresi logistik berganda. Analisis regresi logistik berganda bertujuan mengetahui hubungan status kematian bayi dengan variabel independen secara keseluruhan, variabel yang digunakan adalah variabel yang berhasil terseleksi, maka model persamaan prediksi kemudian dapat dicari persamaan faktor risiko menggunakan transformasi logit yang dinyatakan sebagai berikut:

$$
g(x)=\ln \frac{[\pi(x)\}}{[1-\pi(x)]}=\beta_{0}+\beta_{1} X
$$

\section{HASIL PENELITIAN}

Survei Demografi Kesehatan Indonesia tahun 2012 memuat banyak data yang dikelompokkan menjadi data khusus rumah tangga, data khusus anggota rumah tangga tiap orang, data khusus wanita, data khusus semua kelahiran, data khusus anak, data khusus pria, data khusus pasangan dan data khusus HIV. Penelitian ini menggunakan data khusus wanita yang berisis data wanita pernah kawin. Screening data dilakukan untuk memudahkan dalam menganalisis. Hasil screening data yang dilakukan didapatkan hasil 591 yang memenuhi sebagai responden peneitian. Hasil analisis tabel silang dari 591 responden, dapat dilihat pada gambaran angka kematian bayi di Jawa Timur sebagai berikut.

\section{Gambaran Angka Kematian Bayi}

Tabel 1. menunjukkan bahwa persentase ibu dengan paritas tidak ideal pada ibu yang penah memiliki bayi meninggal lebih kecil dari pada persentase ibu dengan paritas ideal pada ibu yang penah memiliki bayi meninggal. Persentase ibu dengan paritas ideal pada ibu

Tabel 1. Hasil Analisis Tabel Silang Paritas, Penolong Persalinan dan Jarak Kehamilan dengan Angka Kematian Bayi di Jawa Timur

\begin{tabular}{|c|c|c|c|c|c|c|}
\hline \multirow{3}{*}{ Variabel } & \multicolumn{4}{|c|}{ Angka Kematian Bayi } & \multirow{2}{*}{\multicolumn{2}{|c|}{ Total }} \\
\hline & \multicolumn{2}{|c|}{ Ya } & \multicolumn{2}{|c|}{ Tidak } & & \\
\hline & $\mathbf{n}$ & $\%$ & $\mathbf{n}$ & $\%$ & $\mathbf{n}$ & $\%$ \\
\hline \multicolumn{7}{|l|}{ Paritas } \\
\hline Ideal ( $\leq 2$ anak $)$ & 24 & 20,2 & 95 & 79,8 & 119 & 100 \\
\hline Tidak Ideal (>2 anak) & 10 & 2,1 & 462 & 97,9 & 472 & 100 \\
\hline \multicolumn{7}{|l|}{ Penolong Persalinan } \\
\hline Petugaskesehatan & 12 & 14,3 & 72 & 85,7 & 84 & 100 \\
\hline BukanPetugaskesehatan & 22 & 4,3 & 485 & 95,7 & 507 & 100 \\
\hline \multicolumn{7}{|l|}{ Jarak Kelahiran } \\
\hline Tanpa Jarak Kehamilan & 4 & 1,5 & 262 & 98,5 & 266 & 100 \\
\hline$\geq 4$ tahun & 14 & 5,8 & 310 & 94,2 & 247 & 100 \\
\hline$<4$ tahun & 16 & 20,5 & 62 & 79,5 & 78 & 100 \\
\hline
\end{tabular}


yang tidak pernah memiliki bayi meninggal lebih kecil dari pada persentase ibu dengan paritas tidak ideal pada ibu yang tidak pernah memiliki bayi meninggal.

Hasil untuk variabel penolong persalinan adalah persentase ibu ditolong persalinannya bukan oleh petugas kesehatan dan penah memiliki bayi yang meninggal lebih kecil dari pada persentase ibu dengan penolong persalinan petugas kesehatan dan memiliki bayi yang meninggal. Persentase ibu yang ditolong persalinannya oleh petugas kesehatan dan tidak memiliki bayi meninggal lebih kecil dari pada persentae ibu yang ditolong persalinannya bukan oleh petugas kesehatan dan tidak pernah memiliki bayi yang meninggal.

Hasil analisis tabel silang pada variabel jarak kehamilan, menunjukkan bahwa persentase ibu yang memiliki jarak melahirkan kurang dari 4 tahun dan penah memiliki bayi yang meninggal lebih banyak daripada persentase ibu yang tidak memiliki jarak melahirkan dan jarak melahirkan lebih dari 4 tahun pada ibu yang penah memiliki bayi yang meninggal. Persentase ibu yang tidak memiliki jarak melahirkan dan tidak pernah memiliki bayi meninggal lebih besar dari pada presentase ibu yang memiliki jarak melahirkan kurang dari 4 tahun dan lebih dari 4 tahun pada ibu yang tidak pernah memiliki bayi yang meninggal.

\section{Analisis Regresi Logistik Sederhana}

Hasil analisis yang telah dilakukan pada tabel 2 menunjukkan bahwa hasil regresi logistik sederhana untuk variabel paritas menunjukkan bahwa paritas tidak ideal (> 2 anak) mempunyai hubungan dengan status kematian bayi. Nilai odd ratio menunjukkan hubungan yang positif, hal ini berarti kemungkinan ibu dengan paritas lebih dari 2 anak memiliki bayi meninggal lebih besar 0,08 kali dari pada kemungkinan ibu dengan paritas 2 anak atau kurang dari 2 untuk memiliki bayi meninggal.

Variabel penolong persalinan menghasilkan adanya hubungan antara penolong persalinan bukan petugas kesehatan dengan status kematian bayi. Nilai odd ratio atau peluang variabel penolong persalinan menunjukan semakin banyak bayi lahir ditolong bukan oleh petugas kesehatan akan meningkatkan kesempatan 3,67 kali peluang ibu melahirkan dengan kondisi bayi meninggal.

Variabel jarak kehamilan menghasilkan bahwa secara signifikan jarak kehamilan $\leq 4$ tahun dan jarak kehamilan > 4 tahun berhubungan dengan status kematian bayi. Peluang ibu untuk melahirkan bayi yang mengalami kematian naik 16,94 kali, jika jarak kehamilan $\leq 4$ tahun dan naik 3,94 kali, jika jarak kehamilan $>4$ tahun.

Variabel yang berpengaruh secara signifikan dipilih untuk dijadikan kandidat pada regresi logistik berganda. Analisis regresi logistik berganda dilakukan untuk variabel independen paritas, penolong persalinan dan jarak kehamilan karena mempunyai nilai signifikansi $<0,25$.

\section{Analisis Regresi Logistik Berganda}

Hasil regresi logistik berganda pada tabel 3 menujukkan dari semua variabel yang di analisis hanya variabel paritas yang mempunyai hubungan dengan status kematian bayi. Nilai signifikasi di uji Wald sebesar 0,000, sehingga $\mathrm{H}_{0}$ ditolak.

Besarnya kuat hubungan dari hasil analisis dapat dilihat pada nilai exp $(\beta)$ nama lain untuk

Tabel 2. Hasil Analisis Regresi Logistik Sederhana Paritas, Penolong Persalinan dan Jarak Kehamilan dengan Kematian Bayi

\begin{tabular}{lcccc}
\hline \multicolumn{1}{c}{ Variabel } & B & Wald & Sig. & Exp(B) \\
\hline Paritas ( ref. $\leq 2$ anak) & & & & \\
$>$ 2 anak & 2,457 & 39,115 & 0,000 & 11,672 \\
Konstanta & 1,376 & 36,267 & 0,000 & 3,958 \\
\hline $\begin{array}{l}\text { Penolong Persalinan (ref. Petugas Kesehatan) } \\
\text { Bukan Petugas Kesehatan }\end{array}$ & 1,301 & 11,700 & 0,001 & 0,272 \\
Konstanta & 1,792 & 33,021 & 0,000 & 6,000 \\
\hline Jarak Kehamilan (ref. 0 Jarak Kelahiran) & & & & \\
$\leq 4$ Tahun & $-2,828$ & 24,048 & 0,000 & 0,059 \\
> 4 Tahun & $-1,370$ & 5,696 & 0,017 & 0,254 \\
Konstanta & 4,182 & 68,906 & 0,000 & 65,500 \\
\hline
\end{tabular}


Tabel 3. Hasil Analisis Regresi Logistik Berganda Paritas, Penolong Persalinan dan Jarak Kehamilan dengan Kematian Bayi

\begin{tabular}{lcccc}
\hline \multicolumn{1}{c}{ Variabel } & B & Wald & Sig. & Exp(B) \\
\hline $\begin{array}{lccc}\text { Paritas (ref. } \leq 2 \text { Anak) } \\
\text { > 2 Anak }\end{array}$ & & & \\
Penolong Persalinan (ref. Bukan Petugas Kesehatan) & & & & \\
Petugas Kesehatan & 0,753 & 3,303 & 0,000 & 10,154 \\
Konstanta & 0,872 & 6,406 & 0,066 & 2,124 \\
\hline
\end{tabular}

nilai 1/exp ( $\beta$ ) adalah odds ratio (OR). Paritas mempunyai nilai OR sebesar 0,09 , menunjukan ibu yang pernah melahirkan anak lebih dari dua berisiko 0,09 kali untuk mengalami kematian bayi pada kelahiran selanjutnya dari pada ibu yang melahirkan anak kedua atau kurang dari dua anak. Nilai exp ( $\beta)$ didapat dari nilai logaritma natural $(\beta)$ sebesar 2,318. Nilai $(\beta)$ menunjukkan hubungan hubungan yang positif antara paritas dengan status kematian.Semakin paritas lebih dari dua anak meningkat, maka risiko ibu melahirkan bayi yang mengalami kematian bayi meningkat.

Penelitian ini bertujuan untuk memprediksi faktor yang berhubungan dengan status kematian bayi. Faktor yang diprediksi berasal dari model persamaan regresi yang terbentuk. Nilai Hosmer and Lemeshow menjadi alat pada regresi logistik berganda untuk menentukan ketepatan suatu model. Nilai Hosmer and Lemeshow dari hasil analisis sebesar 0,165, sehingga $\mathrm{H}_{0}$ diterima karena lebih dari nilai $\alpha$ $(\alpha=0,05)$. Nilai $\mathrm{H}_{0}$ yang diterima menunjukkan terdapat perbedaan antara model dengan nilai observasinya, sehingga model persamaaan yang terbentuk sudah tepat.

\section{Model Regresi Logistik}

Syarat model telah terpenuhi, maka model dapat dibentuk. Pembentukan model dapat dilakukan dengan menggunakan nilai koefisien $\beta$ pada tabel di atas. Hasil model persamaan yang terbentuk adalah sebagai berikut:

$$
\begin{aligned}
g(x) & =\ln \frac{[\pi(x)\}}{[1-\pi(x)]} \\
& =0,872+2,318 \text { Paritas }+0,753 \text { Penolong persalinan }
\end{aligned}
$$

Hasil model persamaan untuk memrediksikan probabilitas status kematian bayi. Probabilitasnya adalah sebagai berikut:

\section{Probabilitas}

$=\frac{1}{e^{-(0,872+2,318 \text { Paritas }+0,753 \text { Penolong Persalinan })}}$

Hasil yang perhitungan setelah dimasukkan kedalam model adalah 51,573. Nilai prediksi yang lebih dari 0,5 menunjukkan nilai prediksi yang sesuai adalah 1 , dimana 1 merupakan faktor prediksi dari paritas lebih dari dua anak dan penolong persalinan bukan petugas kesehatan. Kesimpulan yang dapat diambil ibu yang melahirkan anak lebih dari duadan penolong persalinan persalinan bukan petugas kesehatan dapat diprediksikan mengalami kematian bayi. Apabila hasil perhitungan menunjukkan nilai kurang dari 0,5 maka responden tidak mengalami kematian bayi, hal tersebut menunjukkan responden tersebut diluar nilai prediksi yang telah ditentukan.

\section{PEMBAHASAN}

\section{Hubungan Antara Paritas dengan Angka Kematian Bayi}

Hasil penelitian menunjukan paritas berhungan dengan status kematian. Hubungan positif dengan status kematian membuat semakin tinggi nilai paritas atau makin banyak anak yang dilahirkan akan membuat risiko ibu melahirkan bayi mati meningkat. Paritas sebagai variabel yang memilki hubungan terkuat dengan kematian bayi.

Penelitian yang pernah dilakukan oleh Nadjib (1999) menunjukan bahwa paritas ibu yang tinggi membuat ibu semakin menggunakan pelayanan kesehatan sehingga dapat menurunkan risiko kematian bayi. Sejalan dengan penelitian Raodah (2011) membuktikan adanya hubungan paritas dengan adanya hubungan antara paritas ibu lebih dari 4 dan penolong persalinan ibu bukan dari petugas kesehatan terhadap kematian bayi. 
Paritas yang terlalu banyak dapat menjadi penyebab munculnya permasalahan terutama kaitannya dengan kesehatan. Terjadinya kehamilan disertai persalinan secara terus menerus berakibat pada semakin tergerusnya pembuluh darah pada dinding rahim disertai dengan semakin hilangnya elastisitas jaringan akibat peregangan pada masa kehamilan hingga persalinan. Kerusakan pada jaringan tubuh memungkinkan timbulnya kelainan dalam kandungan ibu yang akan sangat mempengaruhi kodisi letak janin atau plasenta pada ibu yang dapat mengganggu pertumbuhan janin. Terganggunya pertumbuhan janin dalam kandungan ibu membuat Ibu melahirkan bayi yang kurang sehat (Wiknjosastro, 2007).

Menurut Wiknjosastro (2009), paritas merupakan status wanita dalam melahirkan dilihat dari aspek jumlahnya. Pengertian tersebut dapat menjadi alasan bahwasannya paritas berhubungandengan status kematian bayi. Paritas satu dengan paritas tinggi atau lebih dari dua mempunyai perbandingan angka kematianbayi yang berbeda. Semakin besar nilai paritas, semakin memperbesar risiko kematian bayi. Kondisi ibu saat melahirkan anak pertama dan kedua masih mendapatkan asuhan obstetri yang baik, sedangkan ibu pada paritas tinggi akan kurang mendapat asuhan obstetri yang baik sebagai akibat dari kehamilan yang tidak terencana.

Kehamilan ibu yang pertama akan menurunkan risiko kematian bayi, begitu juga dengan kehamilan kedua. Persalinan yang pernah dilakukan menjadi pengalaman berharga bagi ibu untuk menghadapi kehamilan dan persalinan setelahnya. Ibu tanpa riwayat kelahiran lebih condong untuk menggali informasi berkaitan dengan proses persalinan dan pelayanan yang tepat.

\section{Hubungan Antara Penolong Persalinan Dengan Angka Kematian Bayi}

Hasil analisis regresi logistik berganda menunjukkan tidak terdapat hubungan antara penolong persalinan dengan status kematian bayi. Penolong persalinan masuk dalam model prediksi sehingga penolong persalinnan merupakan faktor risiko dari kematian bayi karena memiliki hubungan dengan status kehamilan meskipun kurang kuat.

Alasan dari sebagian besar ibu lebih memilih kehamilannya untuk ditolong oleh dukun/paraji saat persalinannya tiba adalah dari segi interaksi masyarakat yang cenderung lebih nyaman dengan dukun karena kebiasaan yang yang telahmengenal baik dukun yang menolong persalinan. Lingkungan tinggal yang berada disekitar ibu tinggal membuat jarak untuk proses persalinan menjadi lebih dekat dibandingkan dengan petugas kesehatan serta yang terpenting melihat dari segi ekonomi untuk biaya persalinan. Pemikiran yang telah berkembang lama bahwa persalinan yang ditolong oleh dukun tergolong lebih terjangkau dibandingkan harus ke petugas kesehatan.

Penentuan tempat persalinan menjadi hal penting bagi ibu hamil. Alasan medis selalu disarankan agar ibu hamil melakukan proses persalinan dengan ditolong oleh petugas kesehatan. Ibu yang mengetahui risiko persalinan yang ditolong oleh tenaga kesehatan yang tidak terampil dan standar yang kurang dari fasilitas kesehatan tempat persalinan akan cenderung memilih di Rumah Sakit dengan alasan kenyamanan agar keselamatan ibu dan bayi dapat terjamin. Rumah menjadi alternatif lain bagi ibu untuk melakukan persalinan karena lingkungan yang familiar sehingga tercipta suasana santai dan nyaman karena berada diantara keluarga (MacDougall, 2003).

Penelitan sebelumnya menunjukan adanya komplikasi persalinan sebagai akibat tenaga kesehatan yang tidak terampil berhubungan dengan tingkat kematian bayi (Aeni, 2013). Peneiltian lain dari Wang (2012) tenaga kesehatan yang tidak terampil membuat masyarakat tidak melilih untuk melakukan persalinan di fasilitas kesehatan, sehingga meningkatkan resiko kematian bayi dimasyarakat tersebut. Pelayan kesehatan yang kurang baik berpengaruh terhadap kematian bayi (Septia, 2016).

Tindakan yang diambil Pemeritah dalam menghadapi masalah AKB telah dilakukan dengan membentuk kelas Ibu hamil. Kelas ibu hamil merupakan tempat yang memfasilitasi ibu hamil untuk belajar bersama mengenai kesehatan Ibu. Kelas dibuat kelompok agar saling berbagi pengetahuan, sehingga peningkatan pengetahuan dan ketrampilan saat masa kehamilan hingga sehabis persalinan dapat tercapai.

Kelas berisi tentang bagaimana pengetahuan dan ketrampilan ibu dalam menghadapi kehamilan, merawat diri saat hamil hingga merawat bayi yang baru lahir, mitos tetang ibu hamil, penyakit dan surat kelahiran (Depkes, 2010). 


\section{Hubungan Antara Jarak Kehamilan dengan Angka Kematian Bayi}

Jarak kehamilan memilki hubungan dengan status kehamilan setelah dianalis dengan regresi logistik. Analis bersama variabel lain membuat jarak kehamilan tidak berhungan dengan status kehamilan. Model prediksi yang digunakan untuk mencari faktor resiko dan faktor resiko terkuat membuat jarak kehamilan tidak memiliki hubungan yang kuat, sehingga tidak masuk kedalm model.

Jarak kehamilan adalah faktor yang berpengaruh terhadap masalah kesuburan seorang ibu. Wanita yang mengalami kehamilan lagi dengan cepat setelah kehamilan sebelumnya menandakan keseburan yang baik dari seorang wanita. Sebagain besar penelitian yang pernah dilakukan menunjukkan hubungan antara jarak kelahiran dengan kemampuan anak dalam mempertahankan hidupnya, yaitu dimana ibu yang melahirkan dalam kurun waktu dua tahun sehabis meelahirkan yang terakhir mempunyai risiko yang lebih besar untul melahirkan anak dengan kemampuan bertahan hidup yang kurang dan berakhir dengan kematian. Penelitian lain menemukan hal yang bertolak belakang dimana risiko kematian bayi juga dapat terjadi pada bayi yang memilki rentan kelahiran yang pendek (Awang, 2003).

Dimulai dari 2005 WHO telah berupaya membuat rekomendasi jarak kelahiran yang ideal. Jarak tersebut berada pada rentan dua tahun antar kelahiran, hal ini bertujuan untuk mempersiapkan jika ingin memulai kehamilan sekaligus mereduksi risiko yang akan mungkin terjadi jika mengalami kehamilan berikutnya. Jarak antar kelahiran sebanyak satu tahun atau dua tahun setelah melahikan dapat membuat ibu mempunyai waktu yang cukup untuk memulihkan diri dari masa kehamilan dan persalinan yang telah dilakukan, dan mampu mengoptimalkan pemberian ASI pada anak selanjutnya (Kabano, et.al., 2016).

\section{SIMPULAN DAN SARAN}

\section{Simpulan}

Paritas lebih dari dua mengalami kematian bayi lebih banyak dari pada paritas dua atau kurang. Penolong persalinan bukan petugas kesehatan lebih banyak mengalami kematian bayi dari pada penolong persalinan petugas kesehatan. Jarak kelahiran kurang dari 4 tahun mengalami kematian bayi lebih banyak dari pada jarak kelahiran lebih dari 4 tahun paritas, penolong persalinan dan jarak kelahiran berhubungan secara parsial dengan status kematian bayi. Paritas berhungan dengan status kematian bayi dianalisis dengan regresi logistik berganda. Model prediksi yang terbetuk adalah

Probabilitas
$=\frac{\exp (7,015-2,318 \text { Paritas }-0,753 \text { Penolong persalinan })}{1+\exp (7,015-2,318 \text { Paritas }-0,753 \text { Penolong persalinan })}$

\section{Saran}

Langah yang dapat diambil dalam usaha mengurangi jumlah kematian bayi di JawaTimur, maka pihak terkait dapat melakukan promosi kesehatan berisi anjuran agar Ibu merencanakan kehamilnnya baik dari segi jumlah anak yang seharusnya ideal yaitu 2 dan rentan kehamilan yang optimal (minimal 24 bulan). Upaya pencegahan jangka panjang berupa penundaan usia perkawinan bagi remaja, peningkatan pengetahuan remaja terhadap kesehatan reproduksi melalui pembelajaran di sekolah atau KIR dan peningkatan program pelayanan bina keluarga balita.

\section{DAFTAR PUSTAKA}

Aeni, N. 2013. Faktor Risiko Kematian Ibu. Jurnal Kesehatan Masyarakat Nasional, [ejournal] 7 (10): pp. 453-459.

Awang, H. 2003. Determinants of Waiting Time to Third Pregnancy Using Censored Linear Regression. Journal Biosocial Science, [e-journal] 35 (1): pp. 59-70.

BPS. 2008. Survey Demografi dan Kesehatan Indonesia Tahun 2007. Jakarta: Badan Pusat Statistik.

BPS. 2013. Survei Demografi dan Kesehatan Republik Indonesia Tahun 2012. Jakarta: Badan Pusat Statistik.

BPS Provinsi Jawa Timur. 2012. Indikator Ekonomi dan Sosial Jawa Timur Tahun 2012. Surabaya: Badan Pusat Statistika Provinsi Jawa Timur.

Depkes RI. 2010. Pedoman Pemantauan Wilayah Setempat Kesehatan Ibu dan Anak (PWS-KIA) Puskesmas. Jakarta: Departemen Kesehatan Republik Indonesia.

Dinkes Provinsi Jawa Timur. 2015. Profil Kesehatan Provinsi Jawa Timur 2014. Surabaya: Dinas Kesehatan Provinsi Jawa Timur.

Kabano, I.H., Annelet, B., Pieter, H. 2016. The Effect of Pregnancy Spacing On Fetal 
Survival and Neonatal Mortality in Rwanda: A Heckman Selection Analysis. Journal of Biosocial Science, [e-journal] 48 (3): pp. 358-373.

Kemenkes RI. 2013. Riset Kesehatan Dasar (Riskesdas) 2013. Jakarta: Badan Penelitian dan Pengembangan Kesehatan Departemen Kesehatan Republik Indonesia.

Kemenkes RI. 2015. Kesehatan dalam Kerangka Sistainable Development Goals $\left(S D G^{\prime} S\right)$. Jakarta: Kementerian Kesehatan Republik Indonesia.

MacDougall, J. 2003. Kehamilan Minggu demi Minggu. Jakarta: Penerbit Erlangga.

Masuy-Stroobant, G. 2001. The Determinants of Infant Mortality: How Far are Conceptual Frameworks Really Modelled. Thesis. Universite Catholique de Louvain.

Misra, D.P., Bernard, G., Adam, A. 2003 Integrated Perinatal Health Framework: A Multiple Determinants Model with a Life Span Approach. American Journal of Preventive Medicine, [e-journal] 25 (1): pp. 65-75.

Nadjib, M. 1999. Pemerataan Akses Pelayanan Rawat Jalan di Berbagai Wilayah Indonesia. Disertasi. Universitas Indonesia.

Norton, M. 2005 New Evidence on Birth Spacing: Promising Findings for 49 Improving Newborn, Infant, Child, and Maternal Health, International. Journal of Gynecology and Obstetrics, [e-journal] 89 (S1): pp. S1-S6.

PDPERSI. 2007. Kematian Neonatus di Indonesia (presentase). [online] Availabel at http:// www.pdpersi.co.id/? = showdetailnews\&kode $=$ 490\&tbl=cakrawala.

Pritasari, E. 2013. Regresi Bivariat Poisson Dalam Pemodelan jumlah Kematian Bayi Dan Jumlah Kematian Ibu di Provinsi Jawa Timur. Skripsi. Institut Teknologi Sepuluh Nopember.

Raodah, 2011. Determinan Pemilihan Penolong Persalinan di Wilayah Kerja Puskesmas Camplagian Kabupaten Polewali Mandar. Skripsi. Universitas Indonesia.

Septia, M.D. 2016. Kajian Penyebab Tingkat Kematian Bayi di Desa Kotayasa Kecamatan Sumbang Kabupaten Banyumas. Skripsi. Universitas Muhammadiyah Purwokerto.

Sitorus, R. 2009. Makanan Sehat dan Bergizi. Bandung: Yrama Widya.

Syaifuddin. 2011. Pelayanan Kesehatan Maternal Neonatal. Jakarta: Yayasan Bina Pustaka.

Wang, H.I. 2012. Analisis Upaya Penurunan Angka Kematian Ibu dan Bayi melalui Pelaksanaan Revolusi Kartu Ibu dan Anak di Kabupaten Alor Provinsi Nusa Tenggara Timur. Skripsi. Universitas Indonesia.

Wiknjosastro, H. 2007. Ilmu Kebidanan. Jakarta: Yayasan Bina Pustaka.

Wiknjosastro, H. 2009. Ilmu Kebidanan. Edisi 3, Cetakan 6. Jakarta: Yayasan Bina Pustaka.

WHO. 2012. Health at a glance: Asia/Pacific 2012. Paris: OECD Publishing. 